RESEARCH ARTICLE

\title{
Helminthiasis in dogs of University of Peradeniya premises: a potential public health problem
}

\author{
C.S. Sepalage, P.K. Perera, R.S. Rajakaruna* \\ Department of Zoology, Faculty of Science, University of Peradeniya, Sri Lanka.
}

Received: 25/04/2019; Accepted: 25/01/2020

\begin{abstract}
A sizable population of stray dogs are wandering in the premises of the University of Peradeniya and they ramble and defecate inside the faculty buildings and student hostels. This may pose a public health risk due to wide range of zoonotic parasites strays might harbour. Here we carried out a crosssectional, coprological survey to assess the canine helminthiasis in the Peradeniya university premises. Fresh feacal samples were collected from March to June 2018 and were analyzed using a modified Sheather's sucrose flotation technique. Sixty dogs were sampled, of which $76.6 \%$ was infected with one or more enteric helminths with a higher prevalence in stray dogs $(88.6 \%)$ than owned dogs $(60.0 \%)$. Seven helminth genera were recorded: Toxocara (26.7\%), Spirocerca (26.7\%), Strongyloides (10.0\%), Trichuris (5.0\%), Dipylidium (3.3\%), Capillaria (3.3\%) and Ancylostoma (73.3\%). All seven genera were recorded in the stray dogs while Trichuris was not recorded in the owned dogs. Ancylostoma was the most prevalent infection with the highest intensity (103.4 \pm 198.4 Eggs per gram: EPG). There was no difference in the prevalence of Ancylostoma infections between strays $(60.0 \%)$ and owned dogs $(46.7 \%)$ but the intensity of infection was higher in owned dogs (155.2 EPG); range 2 - 755 EPG) than strays (71.6 EPG; range of 1 - $546 \mathrm{EPG}$ ), irrespective of de-worming. It could be due to development of antihelminthic resistance as routine use likely to accelerate the development of resistance in canine helminths. Except for Capillaria, other six helminths recorded were zoonotic, with a potential of humans acquiring the infections when there is close contact with dogs. Stray dogs may act as reservoirs of these infections for owned dogs and humans and vise versa. In order to control the zoonotic infections, the stray dog population in and around faculties and residential halls, has to be controlled implementing strict rules on feeding strays inside the university premises.
\end{abstract}

Keywords: Canine helminthiasis, zoonoses, public health.

\section{INTRODUCTION}

Dogs have been a human companion for millennia and their significant impact on human life renders the risk for transmission of zoonotic pathogens (Schantz, 1994). There is a 1:8 ratio of dog to human population in Sri Lanka (De Alwis, 2000), accounting for a large stray dog population. Dogs, especially the strays, are competent reservoir hosts of several zoonotic pathogens. Canine helminths such as Toxocara canis, Capillaria, Uncinaria, Strongyloides stercoralis and Spirocera lupi transmitted through soil contaminated eggs and larvae have a significant impact on both animals and humans (Surgan,1980; Traub et al., 2002; Traversa et al., 2014; Zanzani et al., 2014). These parasites have a cosmopolitan distribution throughout tropical and subtropical regions (Bethony et al., 2006; Mandarinopereira etal., 2010; Mateus et al., 2014; Zanzani et al., 2014). Following ingestion of eggs or larvae, or skin penetration of larvae, these will develop into adult worms inside the host's gastrointestinal system or other systems like respiratory or circulatory system. Eggs laid by the female worms will pass out with faeces of the host and remain stable for days, for example in hookworms approximately 3 to 84 days under moist humid conditions until the larvae find a suitable host (Brooker et al., 2006; George, 2017) . Some hookworms ( e.g. Ancylostoma duodenale) can undergo hypobiosis to avoid harsh environmental conditions such as vast temperature changes (Brooker et al., 2006) and can stay dormant for long periods.

Helminth infections can cause severe clinical signs like aneamia, intestinal obstruction, chronic dysentery, epigastric pain, flatulence etc. (Stephenson et al.,2000; Wani et al.,2010; Vercruysse et al., 2011), that eventually lead to the death of the infected animal. Toxocara canis and Ancylostoma are the primary nematodes that affect dogs throughout the world (Traversa et al., 2014). Importantly, adult females can easily transmit the infection by environmental contamination with infective eggs, mainly contaminated soil. They may harbor somatic larvae which can activate during pregnency and/ or lactation. Puppies can get easily affected via milk e.g. Toxocara. Hence the close association between the bitch and puppy can easily transmit the infection to puppy from the bitch (Traversa et al., 2014). Soil moisture and appropriate humidity can influence the development of eggs and larvae in the outside environment (Brooker et al., 2006). The moisture conditions make eggs more viable and infective, while rainfall patterns provide suitable moisture conditions. Hence the transmission of helminth infection is high during rainy season (Gunawardena et al., 2004).

Helminth infection in humans had been a heavy burden in Sri Lanka during early 1900s'and bi-annual treatment with antihlminthic drugs to children aged 3-18 years for decades, together with the implementation of proper excreta disposal methods, reduced the prevalence substantially. A national survey of school children reported 
$6.9 \%$ were infected (Pathmeswaran et al., 2010) which is lower than the threshold of $20 \%$ prevalence to implement mass de-worming programs (WHO, 2006). However, a higher prevalence of $29 \%$ was reported in plantation community (Gunawardena et al., 2011) but this was much less compared to $90 \%$ recorded in early 1990s (Sorensen et al., 1996). Currently, the helminth infections of humans are confined to areas with poor sanitary conditions (De Silva, 2014). Studies have shown that stray dogs harbour a wide variety of parasites and may play a role as they can act as a reservoir harboring certain zoonotic helminths to humans (Perera et al., 2013). A recent more comprehensive study analysed GI parasites of dogs and humans in a socioeconomically challenged estate community and also soil samples from the environment providing important insights into one health approach to potential canine zoonoses (Bandaranayake et al., 2019). Among the canine helminths recorded in Sri Lanka, Ancylostoma caninum, Ancylostoma braziliense and Toxocara canis are the most prevalent zoonoses (Senadhira, 1967a, 1967b; Dissanaike, 1961, 1995; Kannathasan et al., 2012).

Sri Lanka has a large population of stray dogs which are more robust and show tolerance and resistance against many diseases. It is possible that the stray dogs are subclinically infected and may provide a continuous source of infection for humans, pedigree dogs and wildlife. In 2006, with the lobbing of animal activists, a presidential order was passed to implement a "no-kill policy" for the canine strays in Sri Lanka involving "catch-neuter-vaccinaterelease" method (CNVR). This is a more humane approach and has significantly reduced the number of rabies cases over the years. However, many complaints have been allegedly made to local councils about the stray dogs in public places. The major contributory factors for increasing stray dogs include dumping unwanted puppies in public places, dumping garbage on the streets and excessive breeding of pedigreed dogs. The number of stray dogs in the university premises has increased over the years posing a risk to the public, students and staff that reside in the area. Here we investigated helminths harboured by the stray and owned dogs in the premises of the University of Peradeniya to assess their potential as sentinels of parasites of humans.

\section{MATERIALS AND METHODS}

\section{Study site}

University of Peradeniya is located in the central hills of Sri Lanka, where elevation ranges between $473.5 \mathrm{~m}$ to 588.5 $\mathrm{m}$. The university spreads across $7 \mathrm{~km}^{2}$, along the lower slopes of Hantana Mountain range. Climatically university has a mild climate with an annual rainfall of $2000 \mathrm{~mm}$ and an annual mean temperature of $28^{\circ} \mathrm{C}$. The current student population in the University of Peradeniya is about 13,000 of which over 5,000 students are in residential halls located within the university premises. Using a convenient sampling method, sites were selected in the premises of the faculties: Agriculture, Arts, Medicine, Science and Veterinary Sciences as well as five student residential halls: Ramanathan, Hilda Obeysekara, Sangamitta, Wijewardana and Jayathilaka. In addition, university staff quarters in Rajawatta and Mahakanda areas were also sampled. Although the samples were collected from these specific places, these dogs wander in other places of the university as well.

\section{Study animals}

Both stray and owned dogs were sampled including both males and females as well as adults and puppies. Information on age (whether adults or puppies) and gender of each dog were recorded while collecting the samples. Owned dogs that were de-wormed 2-4 times a year were considered as regularly de-wormed. Stray dog samples were collected from the faculties and halls of residence while samples from the owned dogs were from the staff quarter at Rajawatta and Mahakanda areas.

\section{Sample collection}

A total of 60 dogs were sampled to represent approximately $50 \%$ of the dog population in the area. Soon after defecating, a fresh faecal sample was hand-picked into an inverted plastic bag and placed in a cooler. Sample collection was carried out from early morning during 6.00 to 9.00 a.m. for a four month period from March to June 2018. Subsequently, the samples were brought to the Parasitology Research Laboratory in the Department of Zoology, Faculty of Science, University of Peradeniya within 1-2 $\mathrm{h}$ from the collection sites and were stored in a refrigerator at $4{ }^{\circ} \mathrm{C}$ for 1-5 days until processed.

\section{Microscopic analysis of helminth eggs}

The samples were analysed using the modified Sheather's sucrose floatation method as previously described (Perera et al., 2013; Jenkins et al., 2017). Briefly, $3 \mathrm{~g}$ of sample was measured and was mixed with $15 \mathrm{ml}$ of distilled water. Following centrifugation (at $1370 \mathrm{~g}$ for $20 \mathrm{~min}$ ), the supernatant was discarded. Subsequently, the tube with the pellet was filled with Sheather's sugar solution and centrifuged. Following several centrifugation steps the remaining pellet with the suspension $(\sim 0.5 \mathrm{ml})$ was observed under the stereo microscope. The helminth eggs observed under high power (40x10) were identified using both morphology and morphometry according to Taylor et al. (2007). In addition, the number of eggs in $0.5 \mathrm{ml}$ was counted and the number of eggs per gram (EPG) of each faecal sample was calculated as previously described (Perera et al., 2013), assuming that the eggs in all $3 \mathrm{~g}$ of faeces have been concentrated into the final pellet of 0.5 $\mathrm{ml}$ as a result of several centrifugation steps. Identification based on egg morphology and morphometry was further confirmed by the identification of larvae obtained by larval cultures.

\section{Larval cultures}

Larval stages were identified by preparing larval cultures. Fresh faeces were mixed with sterile soil and was placed in a glass beaker. The sample was moistured with a small amount of water, kept the beaker upside down in a Petri dish and the Petri dish was filled with water. The beaker was kept for 3-4 days under sunlight and then water samples were examined under the light microscope for larvae. 


\section{Statistical Analysis}

Infection prevalence and intensity were calculated and were compared between owned and stray dogs using a Chi square test and Mann Whitney U test, respectively using SPSS statistical software version 25.0.

\section{RESULTS}

Faecal samples from 35 stray dogs and 25 owned dogs were collected from the University of Peradeniya premises (Figure 1).

\section{Prevalence of parasites}

Of 60 dogs $76.6 \%$ were infected with one or more helminth species. Between the two categories of dogs, stray dogs had a higher prevalence of infection $(31 / 35 ; 88.6 \%)$ compared to that of owned dogs $(15 / 25 ; 60.0 \%$; Chi square test $\left.\chi^{2}=22.134 ; p<0.0001\right)$. Overall, female dogs had a significantly higher prevalence $(27 / 35 ; 77.1 \%)$ compared to male dogs $\left(16 / 25 ; 64 \% ; \chi^{2}=4.063 ; p=0.044\right)$ but there was no difference in the prevalence of infection between puppies ( $<12$ months; $9 / 12 ; 75 \%$ ) and adults ( $\geq 12$ months; $\left.35 / 48 ; 72.9 \% ; \chi^{2}=0.104 ; p=0.747\right)$.

\section{Parasite diversity and intensity}

Seven helminth genera were recorded (Table 1) of which the most common infection was Ancylostoma (44/60; 73.3\%), followed by Toxocara $(16 / 60 ; 26.7 \%)$ and Spirocerca (16/60; 26.7\%; Figure 2). All seven genera were recorded in the stray dogs while Trichuris, was not recorded in the owned dogs (Figure 2). All helminth genera had a higher intensity of infection (EPG) in strav dogs compared to that of owned dogs, except for Ancylostoma (Table 2). Although there was no difference in the prevalence of Ancylostoma infection between owned dogs $(60.0 \%)$ and stray dogs (46.7\%; Chi square test $\left.\chi^{2}=3.39, p=0.6539\right)$, owned dogs had a higher intensity of Ancylostoma (155.2 EPG) than strays (71.6 EPG; Mann Whitney U test; $\mathrm{U}=190.5$; $p=0.041$ ) and between adults (65.5 EPG) and puppies (242.2 EPG; $\mathrm{U}=87 ; \mathrm{p}=0.041)$. However, there was no difference in the intensity of Ancylostoma infection between females (110.8 EPG) and males (98.4 EPG; $U=213.5 ; p=0.865$ ).

Toxocara infection showed the second highest infection intensity in both owned (62.7 EPG) and stray dogs (48.7 EPG) but there was no significant difference in Toxocara infection between the two groups (Mann Whitney U test; $\mathrm{U}=25.5 ; \mathrm{p}=0.522)$. Further, there was no difference in the Toxocara intensity of infection between females ( 65.7 EPG) and males (27.3 EPG; $U=16.0 ; p=0.097)$ and between puppies (145.0 EPG) and adults (37.9 EPG; U=15.5; $\mathrm{p}=0.060$ ). For Spirocerca, there was no difference in the intensity of infection between stray dogs (31.1 EPG) and owned dogs (18.6; EPG; Mann Whitney U test; $U=22.5$; $\mathrm{p}=0.562)$ or between puppies (48.3 EPG) and adults $(15.8$ EPG; $\mathrm{U}=15.0 ; \mathrm{p}=0.246)$. Among the observed parasite genera Dipylidium, Toxocara, Strogyloides, Trichuris and Ancylostoma have zoonotic potential while Spirocerca has been listed as a very rare zoonotic disease.

\section{DISCUSSION}

The study shows that the dogs in the Peradeniya university premises harbour many helminth infections and the prevalence of infection is higher in stray dogs than owned

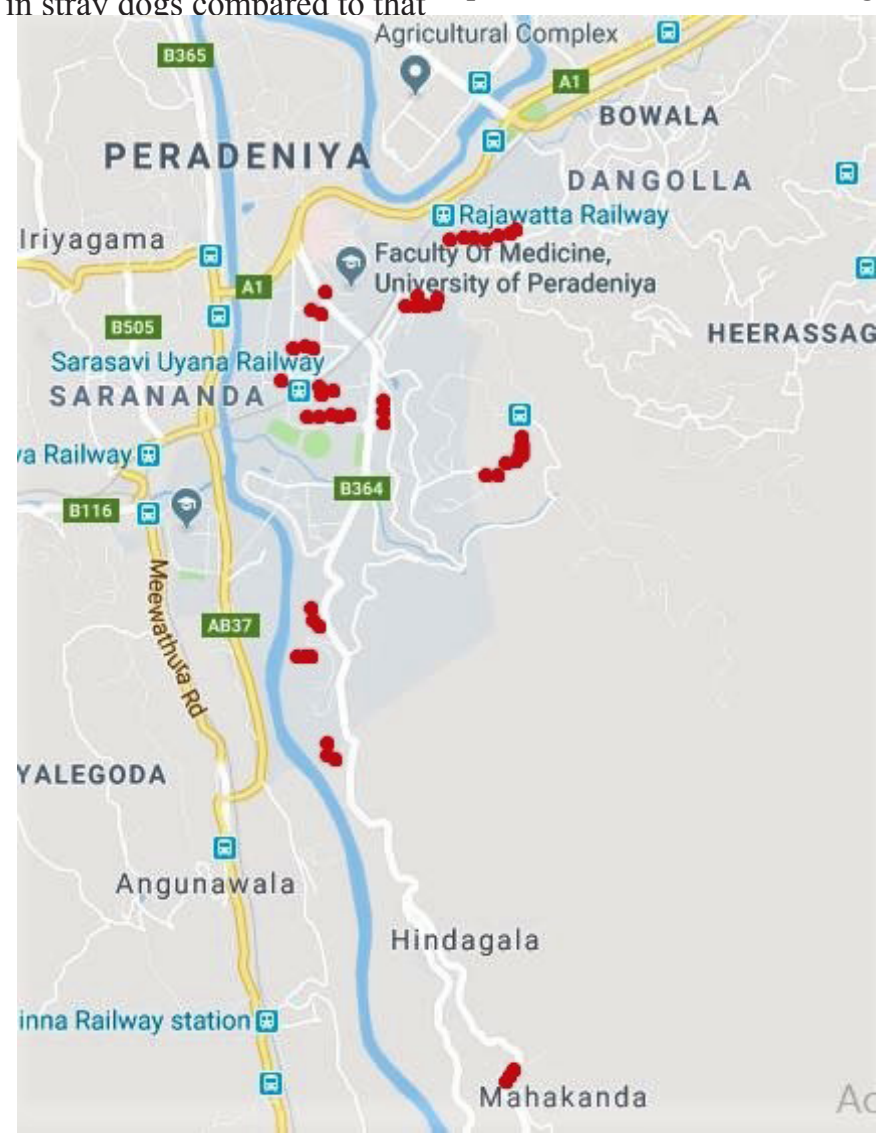

Figure 1: Map of Peradeniya University showing the sample collection sites (red dots). 
Table 1: Prevalance of helminthes among the males and females and adults and puppies of the stray and owned dogs.

\begin{tabular}{|c|c|c|c|c|c|c|c|c|c|}
\hline \multirow{3}{*}{ Helminth } & \multirow{3}{*}{$\begin{array}{c}\text { Overall } \\
\text { Prevalence } \\
(\%)\end{array}$} & \multicolumn{4}{|c|}{ Stray dogs $(35)(\%)$} & \multicolumn{4}{|c|}{ Owned dogs $(25)(\%)$} \\
\hline & & \multicolumn{2}{|c|}{ Gender } & \multicolumn{2}{|c|}{ Age } & \multicolumn{2}{|c|}{ Gender } & \multicolumn{2}{|c|}{ Age } \\
\hline & & $\begin{array}{c}\text { Male } \\
\text { (10) }\end{array}$ & $\begin{array}{c}\text { Female } \\
\text { (25) }\end{array}$ & $\begin{array}{c}\text { Adult } \\
\text { (33) }\end{array}$ & $\begin{array}{c}\text { Puppy } \\
\text { (2) }\end{array}$ & $\begin{array}{c}\text { Male } \\
\text { (15) }\end{array}$ & $\begin{array}{c}\text { Female } \\
\text { (10) }\end{array}$ & $\begin{array}{l}\text { Adult } \\
\text { (15) }\end{array}$ & $\begin{array}{c}\text { Puppy } \\
\text { (10) }\end{array}$ \\
\hline Strongyloides sp. & 10.0 & - & 8.6 & 11.4 & - & 4 & 4 & - & 8 \\
\hline Spirocerca sp. & 26.7 & - & 17.1 & 22.9 & 5.7 & 12 & 12 & 20 & 4 \\
\hline Toxocara sp. & 26.7 & 14.3 & 22.9 & 34.3 & 2.9 & 4 & 8 & 8 & 4 \\
\hline Trichuris sp. & 5.0 & 5.7 & 2.9 & 8.6 & - & - & - & - & - \\
\hline Capilaria sp. & 3.3 & 2.9 & 2.9 & 5.7 & - & 4 & - & 4 & - \\
\hline Dipylidium sp. & 3.3 & - & 11.4 & 11.4 & - & - & 4 & 4 & - \\
\hline Ancylostoma & 73.3 & 31.4 & 51.4 & 74.3 & 2.9 & 32 & 28 & 40 & 20 \\
\hline
\end{tabular}

Table 2: Intensity of infection of helminthes among the males and females and adults and puppies of the stray and owned dogs.

\begin{tabular}{|c|c|c|c|c|c|c|c|c|c|}
\hline \multirow{3}{*}{ Helminth } & \multirow{3}{*}{$\begin{array}{l}\text { Overall } \\
\text { Intensity } \\
\text { Of Infection } \\
\text { (EPG) }\end{array}$} & \multicolumn{4}{|c|}{ Stray dogs $(E P G \pm S D)$} & \multicolumn{4}{|c|}{ Owned dogs $(\mathrm{EPG} \pm \mathrm{SD})$} \\
\hline & & \multicolumn{2}{|l|}{ Gender } & \multicolumn{2}{|l|}{ Age } & \multicolumn{2}{|l|}{ Gender } & \multicolumn{2}{|l|}{ Age } \\
\hline & & Male & Female & Adult & Puppy & Male & Female & Adult & Puppy \\
\hline Strongyloides sp. & $7.7 \pm 4.5$ & - & $10.0 \pm 3.6$ & $\begin{array}{c}8.3 \pm \\
1.5\end{array}$ & 15.0 & 3.0 & 3.0 & - & 3.0 \\
\hline Spirocerca sp. & $24.5 \pm 28.1$ & $\begin{array}{c}43.3 \\
\pm 50.5\end{array}$ & $\begin{array}{c}22.0 \pm \\
23.6\end{array}$ & $\begin{array}{c}19.7 \pm \\
20.1\end{array}$ & 100.0 & $\begin{array}{c}21.3 \pm \\
22.3\end{array}$ & $\begin{array}{c}16.0 \pm \\
21.5\end{array}$ & $\begin{array}{c}11.2 \pm \\
15.8\end{array}$ & $\begin{array}{c}31.0 \pm \\
24.4\end{array}$ \\
\hline Toxocara sp. & $51.3 \pm 81.3$ & $\begin{array}{c}32.6 \pm \\
53.8\end{array}$ & $\begin{array}{c}58.7 \pm \\
99.6\end{array}$ & $\begin{array}{c}42.2 \pm \\
83.5\end{array}$ & 126.0 & 1.0 & $\begin{array}{c}93.5 \pm \\
99.7\end{array}$ & $\begin{array}{c}12.0 \pm \\
15.5\end{array}$ & 164.0 \\
\hline Trichuris sp. & $3.7 \pm 4.6$ & 1.0 & 9.0 & $\begin{array}{c}3.7 \pm \\
4.6\end{array}$ & - & - & - & - & - \\
\hline Capillaria sp. & $4.5 \pm 4.9$ & - & 1.0 & 1.0 & - & 8.0 & - & 8.0 & - \\
\hline Dipylidium sp. & $10.3 \pm 11.3$ & - & $\begin{array}{c}26.0 \pm \\
13.3\end{array}$ & $\begin{array}{c}8.7 \pm \\
13.3\end{array}$ & - & - & 15.0 & 15.0 & - \\
\hline Ancylostoma sp. & $103.4 \pm 198.4$ & $\begin{array}{c}9.5 \pm \\
5.5\end{array}$ & $\begin{array}{c}99.2 \pm \\
177.1\end{array}$ & $\begin{array}{c}54.17 \pm \\
121.9\end{array}$ & $\begin{array}{c}280.5 \pm \\
375.5\end{array}$ & $\begin{array}{c}200.9 \pm \\
284.2\end{array}$ & $\begin{array}{l}96.4 \pm \\
215.3\end{array}$ & $\begin{array}{l}96.0 \pm \\
247.7\end{array}$ & $\begin{array}{c}231.3 \pm \\
259.6\end{array}$ \\
\hline
\end{tabular}

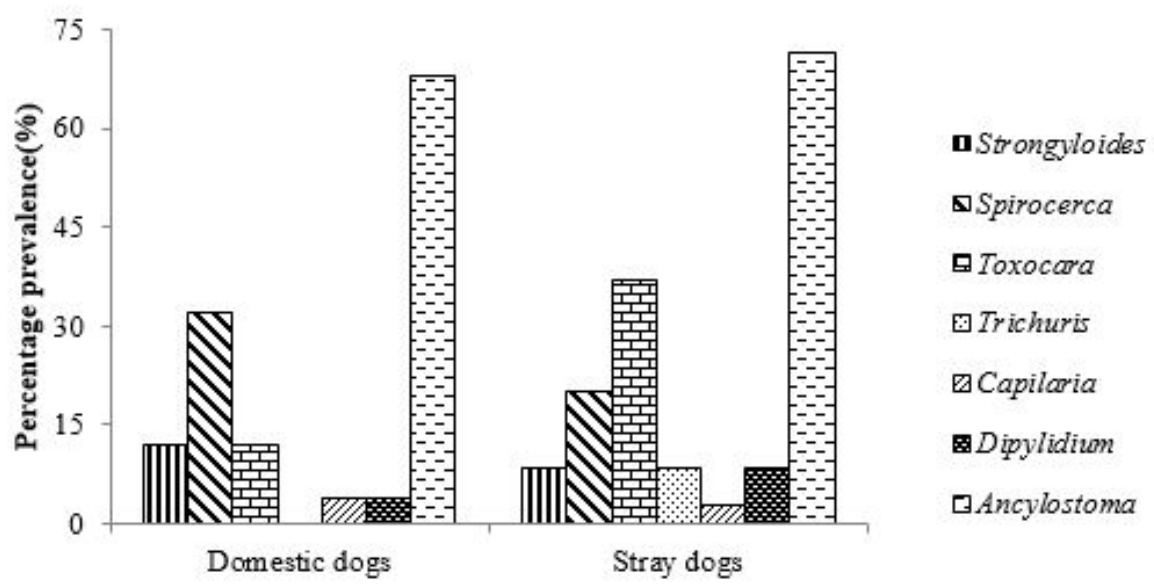

Figure 2: The prevalence of enteric parasites among owned and stray dogs of University of Peradeniya premises. 
dogs. The problem is greater in the free roaming dogs due to more frequent exposure of animals to faeces, and the condition is exacerbated during warm, rainy seasons when temperatures and humidity are increased. Studies show that effect of dog breed is not significant in helminth transmission, where prevalence and intensities of parasites were higher in crosses of local breeds compared to exotic breeds. Similar parasitic prevalences have been recorded in both pure and mixed breeds (Oliveira-Sequeira et al., 2002;Senlik et al., 2006; Aydenizöz-Özkayhanet al., 2008; Perera et al., 2013). Factors like gender of dog, associate environment, nutritional levels, anthelmintic treatment and immune status can affect the prevalence of helminth infections considerably (Bugg et al., 1999; OliveiraSequeira et al., 2002; Scaramozzino et al., 2009).

Stray dogs can be found all over the university premises and are mostly vaccinated against rabies. However, the lack of de-worming and defecation in public areas contribute consideraby to the transmition of infections to other dogs as well as to humans. The most common helminth infection was hookworm, Ancylostoma. A previous study carried out in Hantana area in the Kandy district show high Ancylostoma burden in dogs (Perera et al., 2013). Ancylostoma sheds large number of eggs per week (Traversa, 2012; Traversa et al., 2014). The transmission of hookworm eggs are mainly controlled by climatic conditions, as eggs require warm and moist conditions to develop into larval stages (Sorensen et al., 1994). Heavy infections cause diarrhoea and blood mucus passes with faeces and may also develop severe compensate anaemia (Rep et al., 1971; Carroll and Grove, 1984; Traub, 2013). Four hookworm species are known to infect dogs: Ancylostoma caninum, A. braziliense, A. ceylanicum and Uncinaria stenocephala (Landman and Prociv, 2003; Palmer et al., 2008) of which Ancylostoma spp. primarily occur in moist and warm climatic zones whereas $U$. stenocephala prefers temperate and subarctic regions (Levine, 1980; Bowman, 2009). Among these, A. caninum is one of the most pathogenic of dogs (Bowman et $a l ., 2003$ ) and is also a zoonotic species (Prociv and Croese, 1996). These three species of Ancylostoma have been reported from Sri Lanka (Seneviratna, 1955; Dissanaike, 1961; Kannangara and Karunaratne, 1970). In fact, $A$. ceylanicum was first described from a civet cat in Sri Lanka (Loos, 1911) and later shown to have a high prevalence of $92 \%$ in dogs and occurred in greater numbers than other species of Ancylostoma (Kannangara and Karunaratne, 1970). Ancylostoma ceylanicum is zoonotic and is recorded in humans in India, West New Guinea, Taiwan and the Philippines (Choo et al. 2000). In the present study, both owned dogs and strays were equally infected with Ancylostoma but the intensity of infection was higher in the owned dogs, irrespective of deworming. Generally, dogs respond quickly to antihelminthics and faecal egg counts decrease over time (Nolan et al., 1992). It is recognised that routine use of anthelmintic drugs likely to accelerate the development of resistance in canine helminths as in livestock helminths (Besier and Love, 2003; Moncayo et al., 2008). Currently, however there are limited reports on anthelmintic resistant nematodes of dogs (Raza et al., 2018).
The second most prevalent canine helminth was Toxocara and Spirocerca infections. Toxocara eggs can survive for a long period of time in outside harsh environmental conditions due to the thick protective egg shell with several layers (Mandarino-pereira et al., 2010). Infection occurs when embryonated eggs are ingested. Similar to Ancylostoma, the larval development of Toxocara is determined by soil type, temperature and moisture conditions (Okulewicz et al., 2012). A previous study recorded that $T$. canis is more prevalent in puppies than in adults (Iddawela et al., 1986). Heavily infected pups may continuously whine, shriek and adopt a particular posture by overlapping hind limbs while standing or walking (Raza et al., 2018). Toxocara canis has been recorded in both stray and domestic dogs in previous studies conducted in Sri Lanka (Perera et al., 2013) as well as in many other countries like Nigeria (Ugbomoiko et al., 2008), Malaysia (Mahdy et al., 2012), Poland (Borecka, 2005), Portugal (Mateus et al., 2014), Serbia (Ilić et al., 2017), Australia and other Asian countries (Gordan et al., 2017). Human toxocariasis is present almost all over the world and is the most common zoonotic parasitic infection from pets (Shantz, 1994; Aydenizöz-Özkayhan et al., 2008). It manifests as a number of syndromes including visceral, ocular and subclinical forms causes ocular larva migration in humans (Shantz, 1994; Okulewicz et al., 2012). Spirocerca infection was also common in dogs in the University premises. Spirocercosis in dogs is caused by the nematode Spirocerca lupi. Typical clinical signs are regurgitation, vomiting and dyspnoea. The life-cycle involves an intermediate coprophagous beetle and a variety of paratenic hosts. Larvae follow a specific migratory route, penetrating the gastric mucosa of the host, migrating along arteries, maturing in the thoracic aorta before eventually moving to the caudal oesophagus (Merwe et al., 2008). Here the worm lives in nodules and passes larvated eggs. Early diagnosis of infection is still a challenge and to date no ideal regimen for prophylaxis has been published. Spirocerca lupi has been listed as a very rare zoonotic disease (Goldsmid, 2005).

The dogs also harboured Trichuris, Strogyloides, Capillaria and Dipylidium at low prevalences. Strongyloides infection is highly prevalent in tropical countries and the parasite has significant zoonotic potential (Raza et al., 2018). Larvae are also passed through milk to puppies. It appears that young dogs, especially puppies are more prone to developing clinical strongyloidosis, and $S$. stercoralis infection was associated with the death of a 10week old puppy in a kennel (Dillard et al., 2007). Trichuris was found in adult stray dogs only. It is an ubiquitous parasite all over the world in kennelled, household and shelter dogs (Traversa, 2011). Eggs are difficult to eliminate and serve as a constant source of infection once mixed with soil, and continually expose dogs to re-infection. Thus, the incidence and parasite burden of trichuriasis is higher in adult dogs compared to younger animals (Raza et al., 2018). The second factor that supports the higher prevalence in adult dogs is the absence of trans-mammary or trans-placental routes of transmission (Schantz, 1999). Parasitic infection would be expected to be higher in strays 
where there is contaminated soil in dog environment. Capillaria is an infection with non specific clinical signs, which occur through contaminated food and water and the worm resides in the nasal passage, repiratory tract or the bladder causing nasal, pulmonary and urinary disorders. It usually is not transferable to humans (CDC https://www. cdc.gov/parasites/capillaria/). All the above infections were nematode while Dipylidium was a tapeworm. Infection is acquired by ingestion of infected fleas (Ilić et al., 2017).

Except for Capillaria, other six helminths recorded were zoonotic, with a potential of humans acquiring the infections when there is close contact with dogs. The stray dogs usually do not show symptoms of disease but may act as reservoirs of these infections. Therefore, it is important to raise awareness that people are at risk of exposure as these dogs carry potentially hazardous zoonotic pathogens.

\section{ACKNOWLEDGEMENT}

Financial assistance from the Peradeniya University Grant (No. RG/2016/88/S ) is acknowledged.

\section{DECLARATION OF CONFLICT OF INTEREST}

The Authors declare that there is no conflict of interest.

\section{REFERENCES}

Aydenizöz-Özkayhan, M., Yağc1, B.B. and Erat, S. (2008). The investigation of Toxocara canis eggs in coats of different dog breeds as a potential transmission route in human toxocariasis. Veterinary Parasitology. 152(1-2): 94-100.

Bandaranayaka, K.O., Rajapakse, R.P.V.J. and Rajakaruna, R.S. (2019). Potentially zoonotic gastrointestinal parasites of dogs in Lunugala Tea estate community in Central Sri Lanka. Ceylon Journal of Science. 48(1): 43-50.

Besier, R.B. and Love, S.C.J. (2003). Anthelmintic resistance in sheep nematodes in Australia: The need for new approaches. Australian Journal of Experimental Agriculture. 43(12): 1383-1391.

Bethony, J., Brooker, S., Albonico, M., Geiger, S.M., Loukas, A., Diemert, D. and Hotez, P.J. (2006). Soiltransmitted helminth infections: ascariasis, trichuriasis, and hookworm. The Lancet. 367(9521): 1521-1532.

Borecka, A. (2005). Prevalence of intestinal nematodes of dogs in the Warsaw area, Poland. Helmnthologia. 42(1): 35-39.

Bowman, D.D. (2009). Internal parasites. In Infectious Disease Management in Animal Shelters, 1st ed.; Millar, L., Hurley, K., Eds.Wiley-Blackwell:Ames, IA, USA 1:209-221.

Bowman, D.D., Lynn, R.C. and Eberhard, M.L. (2003) Georgis' Parasitology for Veterinarians. Elsevier Science, St. Louis, USA.

Brooker, S., Clements, A.C. and Bundy, D.A. (2006). Global epidemiology, ecology and control of soil-transmitted helminth infections. Advances in Parasitology. 62: 221-261.

Bugg, R.J., Robertson, I.D., Elliot, A.D. and Thompson, R.C.A. (1999). Gastrointestinal parasites of urban dogs in Perth, Western Australia. The Veterinary
Journal. 157(3): 295-301.

Carroll, S.M. and Grove, D.I. (1984). Parasitological, hematologic, and immunologic responses in acute and chronic infections of dogs with Ancylostoma ceylanicum: a model of human hookworm infection. Journal of Infectious Diseases. 150(2): 284-294.

Choo, J., Pang, E. and Prociv, P. (2000). Hookworms in dogs of Kuching, Sarawak (North Borneo). Transactions of the Royal Society of Tropical Medicine and Hygiene. 94(1): 21-22.

De Alwis, T.M.D.R. (2000). A survey of endoparasitic zoonoses in stray dogs at selected locality in Polonnaruwa District. M Sc thesis, pp. $8-42$. Department of Pathobiology, Faculty of Veterinary Medicine and Animal Sciences, University of Peradeniya, Peradeniya.

De Silva, N. (2014). The neglected tropical diseases in Sri Lanka. Anuradhapura Medical Journal. 8: 30-33

Dillard, K.J.; Saari, S.A. and Anttila, M. (2007). Strongyloides stercoralis infection in a Finnish kennel. Acta Veterinaria Scandinavica. 49(1): 37.

Dissanaike A.S. (1961). On some helminths of dogs in Colombo and their bearing on human infections, with a description of a new trematode Heterophyopsisyehi Nov. (Heterophyidae). Ceylon Journal of Medical Sciences. 10: 1-12.

Dissanaike A.S. (1995). Uncommonly reported parasitic infections of childhood and parasites of the future. Ceylon Journal of the Child Health. 24: 1-8.

George, S. (2017). The role of domestic animals in the transmission of soil-transmitted helminth infections in humans (Doctoral dissertation, Ghent University).

Goldsmid, J.M. (2005). Zoonotic Infections- an overview In: editors..:, 2005. Available at: (accessed Oct 1 2019). In: GOLDSMID, J. \& LEGGAT, P. (eds.) Primer of tropical medicine. Brisbane: ACTM Publications.

Gunawardena, G.S.A., Karunaweera, N.D. and Ismail, M.M. (2004). Wet-days: are they better indicators of Ascaris infection levels?. Journal of Helminthology. 78(4): 305-310.

Gunawardena, K., Kumarendran, B., Ebenezer, R., Gunasingha, M.S., Pathmeswaran, A. and De Silva, N. (2011). Soil-transmitted helminth infections among plantation sector schoolchildren in Sri Lanka: prevalence after ten years of preventive chemotherapy. PLoS Neglected Tropical Diseases. 5(9): p.e1341.

Ilić, T., Kulišić, Z., Antić, N., Radisavljević, K. and Dimitrijević, S. (2017). Prevalence of zoonotic intestinal helminths in pet dogs and cats in the Belgrade area. Journal of Applied Animal Research. 45(1): 204208.

Jenkins, T.P., Rathnayaka, Y., Perera, P.K., Peachey, L.E., Nolan, M.J., Krause, L., Rajakaruna, R.S. and Cantacessi, C. (2017). Infections by human gastrointestinal helminths are associated with changes in faecal microbiota diversity and composition. PloS one. 12(9): p.e 0184719.

Kannangara, D.W.W and Karunaratne, G.M.S. (1970). A note on intestinal helminths of dogs in Colombo. Ceylon Veterinary Journal. 18(2): 47-49.

Kannathasan, S., Murugananthan, A., Rajeshkannan, N. and 
de Silva N.R. (2012). Cutaneous Larva Migrans among Devotees of the Nallur Temple in Jaffna, Sri Lanka. PLoS ONE 7(1): e30516. https://doi.org/10.1371/ journal.pone. 0030516 .

Levine, N.D. Hookworms. (1980). In Nematode Parasites of Domestic Animals and of Man, 2nd ed.; Levine, N.D., Ed.; Burgess Publication: Minneapolis, MN, USA.

Mahdy, M.A., Lim, Y.A., Ngui, R., Fatimah, M.S., Choy, S.H., Yap, N.J., Al-Mekhlafi, H.M., Ibrahim, J. and Surin, J. (2012). Prevalence and zoonotic potential of canine hookworms in Malaysia. Parasites \& Vectors. 5(1): 88 .

Mandarino-Pereira, A., de Souza, F.S., Lopes, C.W.G. and Pereira, M.J.S. (2010). Prevalence of parasites in soil and dog feces according to diagnostic tests. Veterinary Parasitology. 170(1-2): 176-181.

Mateus, T.L., Castro, A., Ribeiro, J.N. and Vieira-Pinto, M. (2014). Multiple zoonotic parasites identified in dog feces collected in Ponte de Lima, Portugal- a potential threat to human health. International Journal of Environmental Research and Public Health. 11(9): 9050-9067.

Moncayo, A.L., Vaca, M., Amorim, L., Rodriguez, A., Erazo, S., Oviedo, G., Quinzo, I., Padilla, M., Chico, M., Lovato, R. and Gomez, E. (2008). Impact of longterm treatment with ivermectin on the prevalence and intensity of soil-transmitted helminth infections. PLoS Neglected Tropical Diseases, 2(9): 293.

Nolan, T.J., Hawdon, J.M., Longhofer, S.L., Daurio, C.P. and Schad, G.A. (1992). Efficacy of an ivermectin/ pyrantel pamoate chewable formulation against the canine hookworms, Uncinaria stenocephala and Ancylostoma caninum. Veterinary Parasitology. 41(12), 121-125.

Okulewicz, A., Perec-Matysiak, A., Buńkowska, K. and Hildebrand, J. (2012). Toxocara canis, Toxocara cati and Toxascaris leonina in wild and domestic carnivores. Helminthologia. 49(1): 3-10.

Oliveira-Sequeira, T.C.G., Amarante, A.F.T., Ferrari, T.B. and Nunes, L.C. (2002). Prevalence of intestinal parasites in dogs from São Paulo State, Brazil. Veterinary Parasitology. 103(1-2): 19-27.

Palmer, C.S., Thompson, R.C., Traub, R.J., Rees, R.; Robertson, I.D. (2008). National study of the gastrointestinal parasites of dogs and cats in Australia. Veterinary Parasitology. 151(2-4): 181-190.

Pathmeswaran, A., Jayatissa, R., Samarasinghe, S., Fernando, A., De Silva, R.P., Thattil, R.O. and De Silva, N.R. (2010). Health status of primary schoolchildren in Sri Lanka. Ceylon Medical Journal. 50: 2.

Perera, P.K., Rajapakse, R.P.V.J. and Rajakaruna, R.S. (2013). Gastrointestinal parasites of dogs in Hantana area in the Kandy District. Journal of the National Science Foundation of Sri Lanka. 41(2): 81-91.

Prociv, P. and Croese, J. (1996). Human enteric infection with Ancylostoma caninum: hookworms reappraised in the light of a "new" zoonosis. Acta Tropica. 62(1): 2344.

Rep, B.H., Joost, K.V. and Vetter, J.C.M., (1971). Pathogenicity of Ancylostoma ceylanicum. VI. Lethal blood loss in hookworm infection. Tropical and Geographical Medicine. 23(2): 184-193.

Scaramozzino, P., Cave D.D., Bettilli, F., D’Orazi, C., Spaziani, A., Mazzanti, S., Scholl, F. and Liberato, C.D. (2009). A study of the prevalence and genotypes of Giardia duodenalis infecting kennelled dogs. The Veterinary Journal. 182: 231-234.

Schantz, P.M. (1994). Of worms, dogs, and human hosts: Continuing challenges for veterinarians in prevention of human disease. Journal of American Veterinary Medicine Association. 204(7): 1023-1028

Schantz, P.M. (1999). Intestinal parasites of dogs in Western Australia: Progress in control and new concerns. Veterinary journal (London, England: 1997), 157(3), p.222.

Senadhira, M.A.P. (1967a). The parasites of Ceylon ii, Trematoda. Ceylon Veterinary Journal 15: 33-41

Senadhira, M.A.P. (1967b). The parasites of Ceylon. IV. Nematoda. A host check list. Ceylon Veterinary Journal, 15: 83-99.

Seneviratna, P. (1955). A checklist of helminths in the Department of Veterinary Pathology, University of Ceylon, Peradeniya. Ceylon Veterinary Journal. 3:3237.

Sorensen, E., Ismail, M., Amarasinghe, D.K.C., Hettiarachchi, I. and Dassenaieke, T.S. (1996). The prevalence and control of soil-transmitted nematode infections among children and women in the plantations in Sri Lanka. Ceylon Medical Journal. 41(2): 37-41.

Sorensen, E., Ismail, M., Amarasinghe, D.K.C., Hettiarachchi, I. and Dassenaieke, T.D.C. (1994). The effect of the availability of latrines on soil-transmitted nematode infections in the plantation sector in Sri Lanka. The American Journal of Tropical Medicine and Hygiene. 51(1): 36-39.

Stephenson, L.S., Latham, M.C. and Ottesen, E.A. (2000). Malnutrition and parasitic helminth infections. Parasitology. 121(S1): S23-S38.

Surgan, M.H., Colgan, K.B., Kennett, S.I. and Paffmann, J.V. (1980). A survey of canine toxocariasis and toxocaral soil contamination in Essex County, New Jersey. American Journal of Public Health. 70(11): 1207-1208.

Taylor, M.A., Coop, R.L. and Wall, R.L. (2007). Parasites of dogs and cats. Veterinary Parasitology. 3: 880.

Traub, R.J. (2013). Ancylostoma ceylanicum, a re-emerging but neglected parasitic zoonosis. International Journal of Parasitology. 43(12-13): 1009-1015.

Traub, R.J., Robertson, I.D., Irwin, P., Mencke, N. and Thompson, R.A. (2002). The role of dogs in transmission of gastrointestinal parasites in a remote tea-growing community in northeastern India. The American Journal of Tropical Medicine and Hygiene. 67(5): 539545.

Traversa, D. (2011). Are we paying too much attention to cardio-pulmonary nematodes and neglecting oldfashioned worms like Trichuris vulpis? Parasites and Vectors. 4(1): 32 .

Traversa, D. (2012). Pet roundworms and hookworms: a continuing need for global warming. Parasites \& Vectors. 5(1): 91. 
Traversa, D., di Regalbono, A.F., Di Cesare, A., La Torre, F., Drake, J. and Pietrobelli, M. (2014). Environmental contamination by canine geohelminths. Parasites \& Vectors. 7(1): 67.

Ugbomoiko, U.S., Ariza, L. and Heukelbach, J. (2008). Parasites of importance for human health in Nigerian dogs: high prevalence and limited knowledge of pet owners. BMC Veterinary Research. 4(1): 49.

van der Merwe, L.L., Kirberger, R.M., Clift, S., Williams M., Keller, N. and Naidoo V. (2008). Spirocerca lupi infection in the dog: a review. Veterinary Journal. 176(3): 294-309.

Vercruysse, J., Albonico, M., Behnke, J.M., Kotze, A.C., Prichard, R.K., McCarthy, J.S., Montresor, A. and Levecke, B. (2011). Is anthelmintic resistance a concern for the control of human soil-transmitted helminths?. International Journal for Parasitology: Drugs and Drug Resistance. 1(1): 14-27.

Wani, I., Rather, M., Naikoo, G., Amin, A., Mushtaq, S. and Nazir, M. (2010). Intestinal ascariasis in children. World Journal of Surgery. 34(5): 963-968.

Zanzani, S.A., Gazzonis, A.L., Scarpa, P., Berrilli, F. and Manfredi, M.T., (2014). Intestinal parasites of owned dogs and cats from metropolitan and micropolitan areas: prevalence, zoonotic risks, and pet owner awareness in northern Italy. Bio Medical Research International. 2014. 